Article

\title{
Estudo do Transporte de Poluentes Atmosféricos no Complexo Industrial e Portuário do Pecém (CIPP), Ceará
}

\author{
Emanuel Santana da $\operatorname{Costa}^{1}$ (D), Alexandre Araújo Costa ${ }^{1}$ \\ ${ }^{1}$ Mestrado Profissional em Climatologia e Aplicações nos Países da CPLP e África, Universidade \\ Estadual do Ceará, Fortaleza, CE, Brasil.
}

Recebido em: 28 de Março de 2021 - Aceito em: 3 de Maio de 2021

\section{Resumo}

\begin{abstract}
O presente trabalho aborda a quantificação e a dispersão de poluentes atmosféricos no entorno de uma indústria siderúrgica em uma zona portuária do litoral do Nordeste Brasileiro (a Companhia Siderúrgica do Pecém, CSP), investigando alguns impactos sobre comunidades e ecossistemas locais. Para esta finalidade, foram analisados os parâmetros medidos pelas estações de monitoramento do órgão ambiental do estado do Ceará sobre os níveis da qualidade do ar no entorno da região onde se encontra instalada a indústria siderúrgica em questão e realizadas simulações matemáticas de dispersão de poluentes. As medidas foram feitas em duas posições: uma, onde se localiza a estação fixa de monitoramento; a outra, onde foi posicionada uma estação móvel por um período limitado. Dada a direção predominante dos ventos atuantes na região, verificou-se que a estação fixa não se mostra capaz de identificar a poluição produzida a partir da indústria siderúrgica, pois a mesma se encontra a barlavento das fontes poluentes. Observou-se em particular que as concentrações de material particulado e gás metano $\left(\mathrm{CH}_{4}\right)$ apresentaram elevação entre as medidas das duas estações de monitoramento, a leste e a oeste da siderúrgica, indicando uma influência direta da instalação industrial na qualidade do ar na região.
\end{abstract}

Palavras-chave: qualidade do ar, poluentes atmosféricos, Industrialização.

\section{Study of the Transport of Atmospheric Pollutants in the Pecém Industrial and Port Complex (CIPP), Ceará, Brazil}

\begin{abstract}
The present work addresses the quantification and dispersion of atmospheric pollutants in the vicinity of a steel industry in a port area on the coast of Northeast Brazil (Companhia Siderúrgica do Pecém, CSP), addressing some impacts on local communities and ecosystems. For this purpose, the parameters measured by the monitoring stations of the environmental agency of the state of Ceará - Brazil, were analyzed on the levels of air quality around the region where the steel industry in question is installed and mathematical simulations of pollutant dispersion were carried out. The measurements were made in two positions: one, where the fixed monitoring station is located; the other, where a mobile station was placed for a limited period. Given the predominant direction of the winds operating in the region, it was found that the fixed station is not able to identify the pollution produced from the steel industry, as it is located windward from the polluting sources. In particular, it was observed that the concentrations of particulate material and methane gas $\left(\mathrm{CH}_{4}\right)$ increased between the measurements of the two monitoring stations, east and west of the steel plant, indicating a direct influence of the industrial installation on the air quality in the region.
\end{abstract}

Keywords: air quality, air pollutants, industrialization.

\section{Introdução}

O Complexo Industrial e Portuário do Pecém (CIPP) foi idealizado visando atrair indústrias de base para estimular a formação de cadeias produtivas, a integração re- gional e a geração de emprego, trabalho e renda, o que, segundo os defensores da implantação dessas indústrias, propiciaria impactos positivos para a qualidade de vida das comunidades no entorno, e a sociedade em geral. Localizada nos municípios de Caucaia e de São Gonçalo do

Autor de correspondência: Emanuel Santana da Costa, emanuelcosta.eng@gmail.com. 
Amarante, litoral oeste do estado do Ceará, a aproximadamente $50 \mathrm{~km}$ de Fortaleza - Ceará, a área do CIPP está inserida em terrenos de Tabuleiros Pré-litorâneos e da Depressão Sertaneja, exibindo uma topografia planificada a suavemente ondulada, com cotas médias de $30,0 \mathrm{~m}$, e ainda, com algumas elevações de maciços residuais, conforme CENTEC (2009) citado por Silva (2014).

O CIPP limita-se ao norte com a Estação Ecológica do Pecém, ao sul com a rodovia BR-222, a leste com a rodovia CE-421 e a oeste com a CE-156. Atualmente o CIPP, além do Terminal Portuário do Pecém, conta com usinas termelétricas, empresas de recepção, armazenagem e exportação de minério (Silva, 2014), além da siderúrgica recém-inaugurada em junho de 2016 (CSP, 2019). Em particular, a Companhia Siderúrgica do Pecém (CSP) tem capacidade instalada para a produção de 3 milhões de toneladas de placas de aço/ano na primeira fase do projeto (CSP, 2019).

O uso de combustíveis fósseis, em especial do carvão mineral, é amplamente empregado na produção mundial de ferro e aço $(98,5 \%)$, sendo a produção de material particulado um dos principais problemas associados a ela (Oliveira, 2014). Do ponto de vista da poluição atmosférica no contexto atual do CIPP, destacam-se as emissões da siderúrgica e da termelétrica, já que ambas são alimentadas por carvão mineral. Tais emissões incluem, além do dióxido de carbono, principal gás de efeito estufa de vida longa emitido por atividades antrópicas, uma variedade de outros poluentes de vida curta, incluindo monóxido de carbono, material particulado, óxidos de nitrogênio etc.

De acordo com o estudo de dispersão atmosférica do Estudo de Impacto Ambiental da região realizado em 2010 (Oliveira, 2010), a CSP contribui para a bacia aérea com $44 \%$ das fontes totais e $85,7 \%$ das fontes pontuais (chaminés) e, com efeito, a nível local são recorrentes as reclamações da população do entorno do CIPP, como exemplo temos citações nos jornais da região metropolitana de Fortaleza:

\footnotetext{
"Poluição no Pecém causa retirada de famílias do entorno ...Os impactos ambientais ocasionados pelas atividades no CIPP têm afetado as comunidades da região há pelo menos seis anos e forçam a saída de famílias no entorno...” (O Povo, 2018).

"Moradores do Pecém voltam a sofrer com fuligem de carvão mineral da CSP." (Diário do Nordeste, 2019).
}

No entanto, informações da empresa e até mesmo do órgão de fiscalização estadual minimizam o problema. Segundo a CSP, a empresa tem nível de emissões de poluentes (não incluindo o $\mathrm{CO}_{2}$ ) $50 \%$ menor que o estabelecido na legislação (SEMACE, 2017) e, segundo notícia veiculada no site do órgão ambiental do estado,

\footnotetext{
"A qualidade do ar na região do Complexo Industrial e Portuário do Pecém é 'boa'. É o que indicam os parâmetros avaliados pela Superintendência Estadual do Meio Ambiente (Semace), por meio da estação de monitoramento da qualidade do ar, mantida
}

pela autarquia, na Estação Ecológica do Pecém, em São Gonçalo do Amarante" (SEMACE, 2019).

A contradição evidente entre tais informações demanda investigação independente, objeto desse estudo. Diante do exposto, vem à tona a problemática a respeito do posicionamento adequado das estações de monitoramento de emissões atmosféricas e as externalidades negativas causadas pela poluição ao meio ambiente e à população.

\section{Materiais e Métodos}

Este trabalho se subdivide em duas linhas de atuação complementares. No primeiro momento, foram avaliados os dados de monitoramento da qualidade do ar das estações do Órgão ambiental do Estado do Ceará (SEMACE) com aquisições de concentrações de gases e poluentes de uma estação fixa denominada "UM-CIPP" e outra estação móvel, que de modo semelhante à primeira, coleta dados e dispõe de condições de ser transportada sobre rodas para diferentes localidades, e que no caso específico deste estudo será denominada "UM-PARADA", em referência a comunidade homônima.

O lapso temporal que permitiu a coleta de dados simultaneamente das estações supracitadas ocorreu no período de 14/08/2019 a 14/09/2019. Os dados foram extraídos da plataforma on-line e trabalhados em planilha para elaboração dos gráficos das séries temporais.

No segundo momento, o estudo foi complementado por modelagem computacional de trajetórias de dispersão de poluentes; trajetórias reversas; e modelagem de deposição de poluentes utilizando para isso a aplicação HYSPLIT $^{\circledR}$ com dados meteorológicos de reanálise para o período de estudo.

\subsection{Estações de monitoramento de qualidade do ar}

Para fins de embasamento empírico, como referido, utilizaram-se duas estações de monitoramento. A primeira estação denominada estação "UM-CIPP”, posicionada e identificada pelas coordenadas de Latitude: -3,5560 / Longitude: $-38,8367\left(3^{\circ} 33^{\prime} 21.6^{\prime \prime} \mathrm{S} 38^{\circ} 50^{\prime} 12.0^{\prime \prime} \mathrm{W}\right)$ na

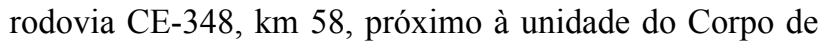
Bombeiros e a segunda estação nominada "UM-Parada" designando a unidade móvel que, no período analisado, esteve posicionada na localidade denominada "Parada", nas coordenadas de Latitude: -3,5684 / Longitude: $-38,8842\left(3^{\circ} 34^{\prime} 04.8^{\prime \prime} \mathrm{S} 38^{\circ} 53^{\prime} 07.9^{\prime \prime} \mathrm{W}\right)$. As duas estações posicionadas respectivamente a nordeste e a oeste da chaminé da siderúrgica "CSP - Companhia Siderúrgica do Pecém" - coordenadas Latitude: -3,5797 / Longitude: $-38,8570\left(3^{\circ} 34^{\prime} 46.9^{\prime \prime}\right.$ S 38 51'25.4" W). Ver indicação na Fig. 1. Ambas as estações estão a cerca de $2,4 \mathrm{~km}$ da empresa. No que diz respeito às Estações de monitoramento da SEMACE, estas consistem de gabinete à prova d'água providas de instrumentação especifica (ver Fig. 2) 


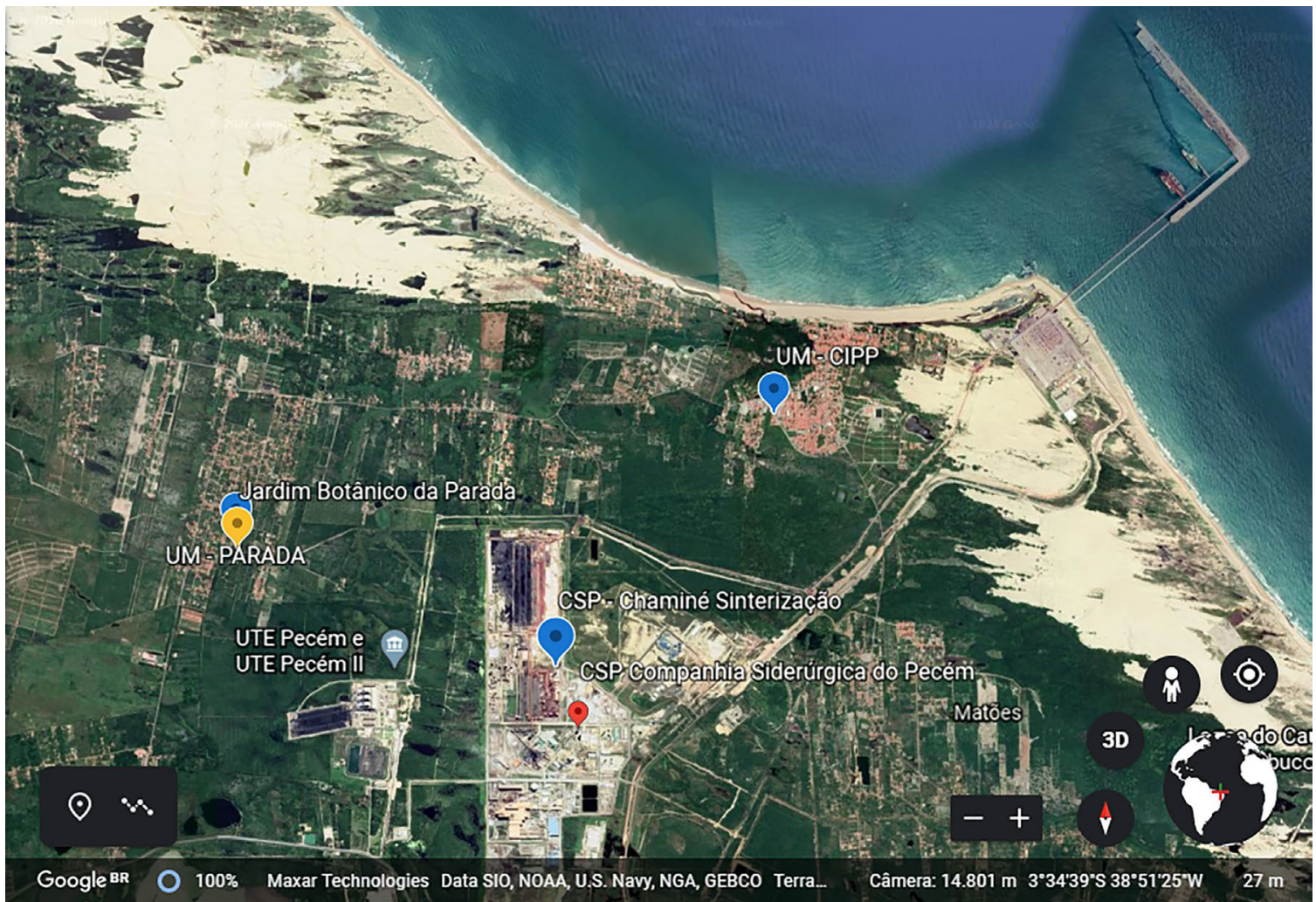

Figura 1 - Imagem de satélite com indicação das Estações de Monitoramento do ar no Pecém "UM-CIPP"; na comunidade da Parada "UM-Parada" e a localização da siderúrgica - CSP. Fonte: Google Earth (2020).
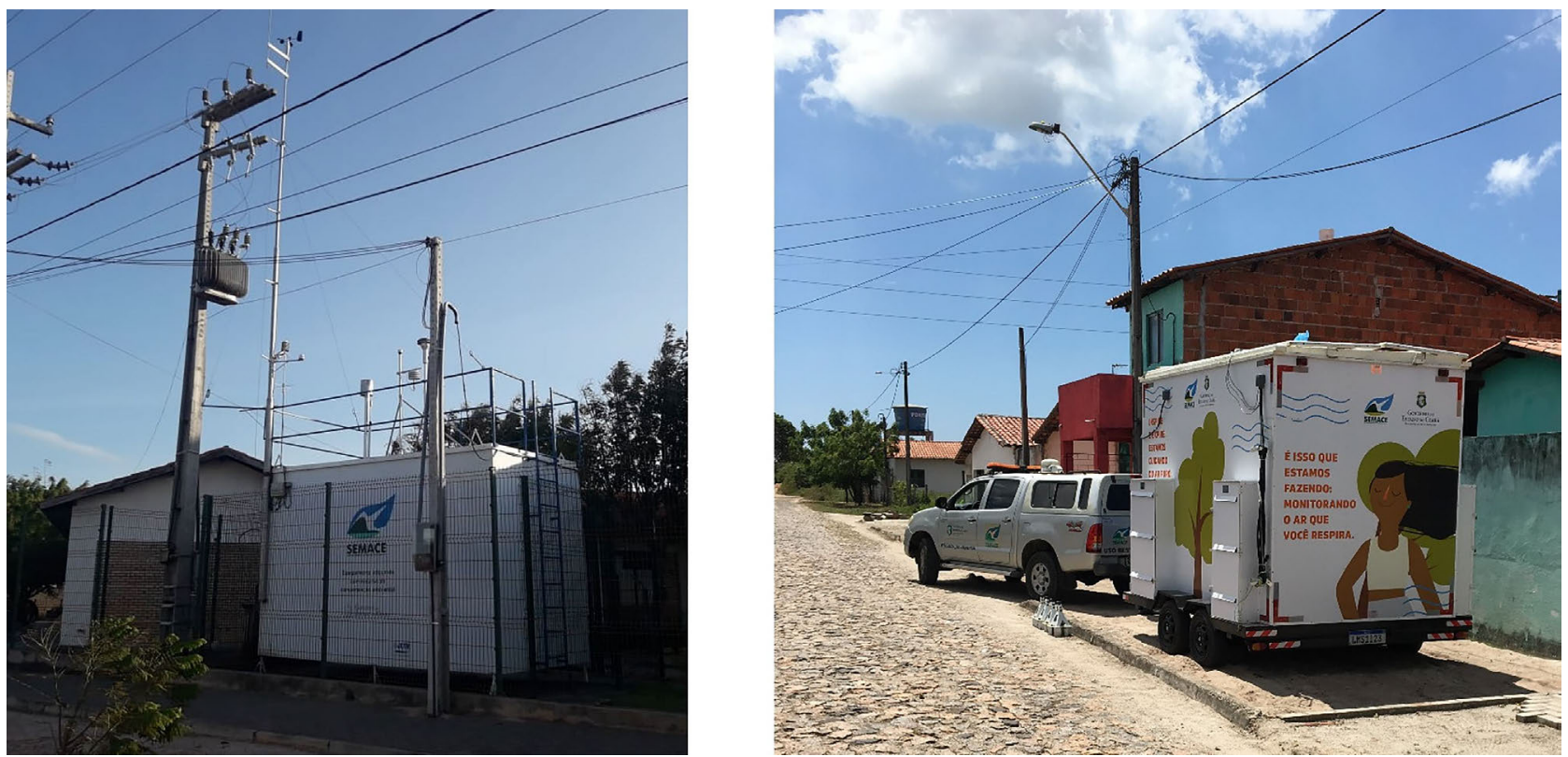

Figura 2 - Estações de Monitoramento do ar; Estação fixa no Pecém "UM-CIPP” e Estação móvel que foi utilizada na comunidade da Parada "UMParada". Fonte: O Autor.

onde a amostra é analisada em tempo real através de métodos óptico-eletrônicos e mede de forma automática, isto é, sem a necessidade de um observador presencial.
Neste trabalho nos limitamos as análises dos seguintes gases e poluentes: Metano $\left(\mathrm{CH}_{4}\right)$; Óxidos de Nitrogênio ( $\mathrm{NO}, \mathrm{NO}_{2}$ e NOx); Ozônio $\left(\mathrm{O}_{3}\right)$ e Partículas 
Totais em Suspensão (PTS). Essas medições foram realizadas através dos métodos: de ionização por chama para o Metano $\left(\mathrm{CH}_{4}\right)$; quimiluminescência para os Óxidos de Nitrogênio ( $\mathrm{NO}, \mathrm{NO}_{2}$ e $\left.\mathrm{NOx}\right)$; absorção de ultravioleta para o Ozônio $\left(\mathrm{O}_{3}\right)$ e absorção de raios beta para Partículas Totais em Suspensão (PTS). As médias/máximas calculadas de acordo com os padrões nacionais de qualidade do ar e as recomendações da Organização Mundial da Saúde (OMS), que consideram como limite o tempo de exposição de um indivíduo a um determinado poluente, acima do qual pode causar danos à saúde. Os dados extraídos da plataforma on-line da SEMACE foram trabalhados em planilha EXCEL ${ }^{\circledR}$, sendo então elaborados gráficos das séries temporais.

\subsection{Modelo computacional}

Para a simulação computacional de trajetórias para frente (forward trajectories), a partir da posição da chaminé da sinterização da siderúrgica CSP e trajetórias reversas (backward trajectories), a partir das posições das estações de monitoramento do CIPP e da Parada utilizouse o simulador HYSPLIT ${ }^{\circledR}$ (abreviatura do inglês HYbrid Single-Particle Lagrangian Integrated Trajectory), desenvolvido pela National Oceanic and Atmospheric Administration (NOAA). O método de cálculo do modelo HYSPLIT $^{\circledR}$ é um híbrido entre a abordagem Lagrangiana, que usa um quadro de referência móvel à medida que os pacotes aéreos se movem de sua localização inicial, e a abordagem Euleriana, que usa uma grade tridimensional fixa como quadro de referência (Silva, 2013). No modelo, os cálculos de advecção e difusão são feitos em uma estrutura Lagrangiana após o transporte da parcela aérea, enquanto as concentrações de poluentes são calculadas em uma grade fixa Stein et al. (2015).

Os parâmetros usados no modelo computacional são os dados climáticos de reanálise da National Oceanic and Atmospheric Administration (NOAA), com arquivos disponíveis desde 06/2019 a atualmente. Os dados são ordenados em uma grade global GFS $0,25^{\circ} \mathrm{e}$ incluem vetores de vento e temperatura. Para o modelo de trajetórias foi utilizada a altura de chaminé de $50 \mathrm{~m}$ e tempo total de rotina de $3 \mathrm{~h}$ com início de uma nova trajetória a cada $1 \mathrm{~h}$ e com um número máximo de 4 trajetórias. A escolha desses parâmetros para as simulações foi feita de modo a não causar a saturação visual pela sobreposição de trajetórias. O modelo HYSPLIT ${ }^{\circledR}$ foi executado de forma interativa na web.

Para a etapa de deposição também utilizando as mesmas condições de localização da modelagem das trajetórias e devido não ter acesso aos dados de concentração, taxa de lançamento e composição química dos gases emanados pela siderúrgica "CSP" foram utilizadas opções padrão oferecidas pelo software HYSPLIT ${ }^{\circledR}$. Realizada a simulação considerando um poluente genérico com 1 unidade de massa liberada continuamente por $1 \mathrm{~h}$ e transpor- tando o poluente por $12 \mathrm{~h}$ na direção dos ventos. Assim, as concentrações resultantes representarão um fator de diluição em vez de concentrações reais de ar e também fornecerão uma "pegada" do padrão de dispersão (fator de diluição). Sem deposição úmida e com uma taxa de deposição seca padrão de $0,001 \mathrm{~m} / \mathrm{s}$ recomendado pelo software se o valor da deposição seca para o caso deste fator ser desconhecido.

A deposição (forward trajectories) partindo da posição da chaminé da siderúrgica CSP está apresentada nos gráficos gerados individualmente para o dia 14/08 e 14/09/ 2019 através do modelo HYSPLIT ${ }^{\circledR}$.

\section{Resultados e Discussão}

As emissões atmosféricas têm vários efeitos na qualidade do ar e variações na concentração desses gases ocorrem em várias escalas de tempo, principalmente, como resultado das emissões antrópicas. A seguir os resultados e discussão a respeito:

\subsection{Metano $\left(\mathrm{CH}_{4}\right)$}

Os resultados do monitoramento do gás metano $\left(\mathrm{CH}_{4}\right)$ na estação "UM-CIPP" e "UM Parada" apresentaram respectivamente concentrações médias de 1,89 ppm e de 2,21 ppm (partes por milhão). A Resolução CONAMA N ${ }^{\circ}$. 491/2018 (BRASIL,2018) não estabelece valores de referência para o metano. Entretanto, os valores encontrados caracterizam o ar como limpo nas imediações da estação "CIPP" e valores tendendo ao poluído na "UMParada" em referência a literatura encontrada em Mihelcic e Zimmerman (2018) que cita que para ambientes limpos a concentração de Metano $\left(\mathrm{CH}_{4}\right)$ varia de 1,0 a $1,9 \mathrm{ppm}_{\mathrm{v}} \mathrm{e}$ $<2,5 \mathrm{ppm}_{\mathrm{v}}$ para ambientes poluídos.

\section{2. Óxidos de nitrogênio ( $\left.\mathrm{NO} / \mathrm{NO}_{2} / \mathrm{NOx}\right)$}

Os resultados das medições de concentração média encontradas para o Monóxido de Nitrogênio (NO) foram de $1,07 \mu \mathrm{g} / \mathrm{m}^{3}$ e de $0,85 \mu \mathrm{g} / \mathrm{m}^{3}$, respectivamente para estação "UM-CIPP" e "UM Parada", mas com máximos bem mais pronunciados nesta última (em várias ocasiões excedendo $5 \mu \mathrm{g} / \mathrm{m}^{3}$ e tendo atingido um máximo, no período de monitoramento, de $9,5 \mu \mathrm{g} / \mathrm{m}^{3}$. A Resolução CONAMA $\mathrm{N}^{\mathrm{o}}$. 491/2018 não estabelece limites para essa substância.

O Dióxido de Nitrogênio $\left(\mathrm{NO}_{2}\right)$ apresentou concentrações médias de $3,6 \mu \mathrm{g} / \mathrm{m}^{3}$ e $5,3 \mu \mathrm{g} / \mathrm{m}^{3}$, respectivamente para "UM-CIPP" e "UM Parada" e, assim como para o $\mathrm{NO}$, os valores máximos foram consistentemente mais elevados na segunda estação, excedendo várias vezes os valores de $20 \mu \mathrm{g} / \mathrm{m}^{3}$. Os valores máximos encontrados foram respectivamente $12,0 \mu \mathrm{g} / \mathrm{m}^{3}$ ("UM-CIPP") e $29,0 \mu \mathrm{g} / \mathrm{m}^{3}$ ("UM Parada"), ambos abaixo dos valores de referência da OMS mencionados na Resolução CONAMA $\mathrm{N}^{\circ}$. 491/2018 $\left(200 \mu \mathrm{g} / \mathrm{m}^{3}\right.$ para valor horário e $40 \mu \mathrm{g} / \mathrm{m}^{3}$ anual). 
Por fim os Óxidos de Nitrogênio Totais $\left(\mathrm{NO}_{\mathrm{x}}\right)$ resultaram em $5,3 \mu \mathrm{g} / \mathrm{m}^{3}$ e $6,8 \mu \mathrm{g} / \mathrm{m}^{3}$ respectivamente nas estações "UM-CIPP" e "UM-Parada" como concentrações médias, com valores máximos, também respectivamente, de $15 \mu \mathrm{g} / \mathrm{m}^{3}$ e $37 \mu \mathrm{g} / \mathrm{m}^{3}$. Foi percebido visualmente que as curvas são concordantes umas com as outras, ou seja, os picos e vales coincidem em muitos momentos. Os resultados gráficos das séries temporais das concentrações desses gases são apresentados respectivamente nas Figs. 3a, 3b e $3 c$.

De acordo com a SEMACE (2019) as principais fontes de óxido nítrico (NO) e dióxido de nitrogênio $\left(\mathrm{NO}_{2}\right)$ são os motores dos automóveis. As usinas termelétricas e indústrias que utilizam combustíveis fósseis contribuem em menor escala. Mas o que se observa neste trabalho é que há um aumento nas concentrações dos óxidos de Nitrogênio $\left(\mathrm{NO}_{2} / \mathrm{NOx}\right)$ da estação "UM-CIPP" para a "UM-Parada", ou seja, ocorre um certo grau de degradação da qualidade do ar.

Embora o valor desta última seja maior que na primeira, pode se afirmar que estes níveis encontrados nas imediações de ambas as estações atendem aos padrões de referência estabelecidos na Resolução CONAMA No $.491 /$ 2018 que prevê limites de $260 \mu \mathrm{g} / \mathrm{m}^{3}$ como padrão da qualidade do ar intermediário até $200 \mu \mathrm{g} / \mathrm{m}^{3}$ como padrão da qualidade do ar final.

\subsection{Ozônio $\left(\mathrm{O}_{3}\right)$}

Em relação ao monitoramento do gás Ozônio $\left(\mathrm{O}_{3}\right)$ na estação "UM-CIPP" e "UM Parada" as respectivas concentrações encontradas para a máxima média móvel obtida no dia para o período de referência de $8 \mathrm{~h}$ foram de $38,7 \mu \mathrm{g} / \mathrm{m}^{3}$ (19,3 ppb) e de $52,6 \mu \mathrm{g} / \mathrm{m}^{3}$ (26,3 ppb). O resultado gráfico da série temporal da concentração do Ozônio está apresentado na Fig. 4. Embora o valor desta última seja maior que na primeira, o ar ainda pode ser enquadrado como limpo nas imediações de ambas as estações em referência a Resolução CONAMA Nº. 491/2018 (BRASIL,2018) que prevê de $140 \mu \mathrm{g} / \mathrm{m}^{3}$ como padrão da qualidade do ar intermediário, valor a ser alcançado em etapas até $100 \mu \mathrm{g} / \mathrm{m}^{3}$ como padrão da qualidade do ar final, valor guia definido pela Organização Mundial da Saúde - OMS em 2005 e corroborado pela literatura em Mihelcic e Zimmerman (2018) que cita que para ambientes limpos a concentração de Ozônio $\left(\mathrm{O}_{3}\right)$ varia de 10 a $100 \mathrm{ppb}_{\mathrm{v}}$, indo para $<350 \mathrm{ppb}_{\mathrm{v}}$ para ambientes poluídos. Comparativamente, as medições locais se apresentaram levemente abaixo do medido no monitoramento de Ferreira Júnior (2016), que obteve de outubro a dezembro de 2015, concentrações do poluente ozônio $\left(\mathrm{O}_{3}\right)$ com médias de $79,2 \mu \mathrm{g} / \mathrm{m}^{3}$ para $8 \mathrm{~h}$ no período de $09 \mathrm{~h}$ às $17 \mathrm{~h}$ e de $60,4 \mu \mathrm{g} / \mathrm{m}^{3}$ para $24 \mathrm{~h}$ na região central do município de São Gonçalo do Amarante/CE.

Os valores mais elevados na "UM-Parada" e a ausência de padrões característicos da circulação de veículos automotores/trânsito urbano sugere que a combustão nas caldeiras da CSP (e possivelmente de outras empresas) combinado aos precursores de ozônio (óxidos de nitrogênio) na presença de luz solar é fonte relevante desse poluente no entorno.

\subsection{Partículas Totais em Suspensão (PTS)}

As Partículas Totais em Suspensão (PTS) de acordo com a resolução CONAMA $\mathrm{N}^{\circ}$ 491/2018 são partículas de material sólido ou líquido suspensas no ar, na forma de poeira, neblina, aerossol, fuligem, entre outros, com diâmetro aerodinâmico equivalente de corte de 50 micrômetros $(50 \mu \mathrm{m})$. As concentrações médias encontradas de PTS foram de $51,5 \mu \mathrm{g} / \mathrm{m}^{3}$ e de $53,9 \mu \mathrm{g} / \mathrm{m}^{3}$ respectivamente nas estações "UM-CIPP" e "UM-Parada" (ver Fig. 5). No período observado, esses valores ficaram dentro dos limites estabelecidos na Resolução CONAMA Nº. 491/2018 que prevê limites de $240 \mu \mathrm{g} / \mathrm{m}^{3}$ como padrão da qualidade do ar na média de 24 h. O legislado na Resolução CONAMA N ${ }^{\circ}$. 491/2018 também estabelece que o valor anual médio limite de PTS é de $80 \mu \mathrm{g} / \mathrm{m}^{3}$. Contudo, os dados disponíveis não permitem constatar o atendimento ou não a este requisito.

O monitoramento de gases ao longo do tempo, portanto, fornece uma compreensão da linha de base, com a qual as alterações induzidas pela atividade futura podem ser comparadas quantitativamente e comprovadas às variações associadas às emissões antropogênicas.

\subsection{Trajetórias de simulação computacional das emissões com o HYSPLIT ${ }^{\circledR}$}

As simulações realizadas para verificar a projeção dos gases poluentes em suas trajetórias para frente (forward trajectories), a partir da posição da chaminé da sinterização da siderúrgica $\mathrm{CSP}$, resultaram, como local de destino a comunidade da Parada.

As simulações realizadas para verificar a trajetória reversa (backward trajectories), dos gases poluentes que chegam à estação de monitoramento "UM-CIPP" resultou como área de captação dos gases, principalmente os ares da região sobre a estação ecológica e, de certa forma da projeção do Oceano Atlântico que margeia a região. Já a trajetória reversa dos gases poluentes que chegam à estação de monitoramento "UM-Parada" resultaram, como área de captação dos gases, os ares da região sobre a área industrial da siderúrgica CSP.

Para consolidar o estudo foi feita a sobreposição dos cenários simulados através da montagem das trajetórias de partículas tanto das que saem da área industrial da siderúrgica CSP quanto das trajetórias que atingiriam as estações "UM-CIPP" e a estação móvel "UM-Parada", simuladas para o dia 14 de agosto de 2019 (Ver Fig. 6).

Quanto ao posicionamento das estações de monitoramento, observa-se que não há sobreposição de trajetórias, e que este fato pode ter contribuído para que os 

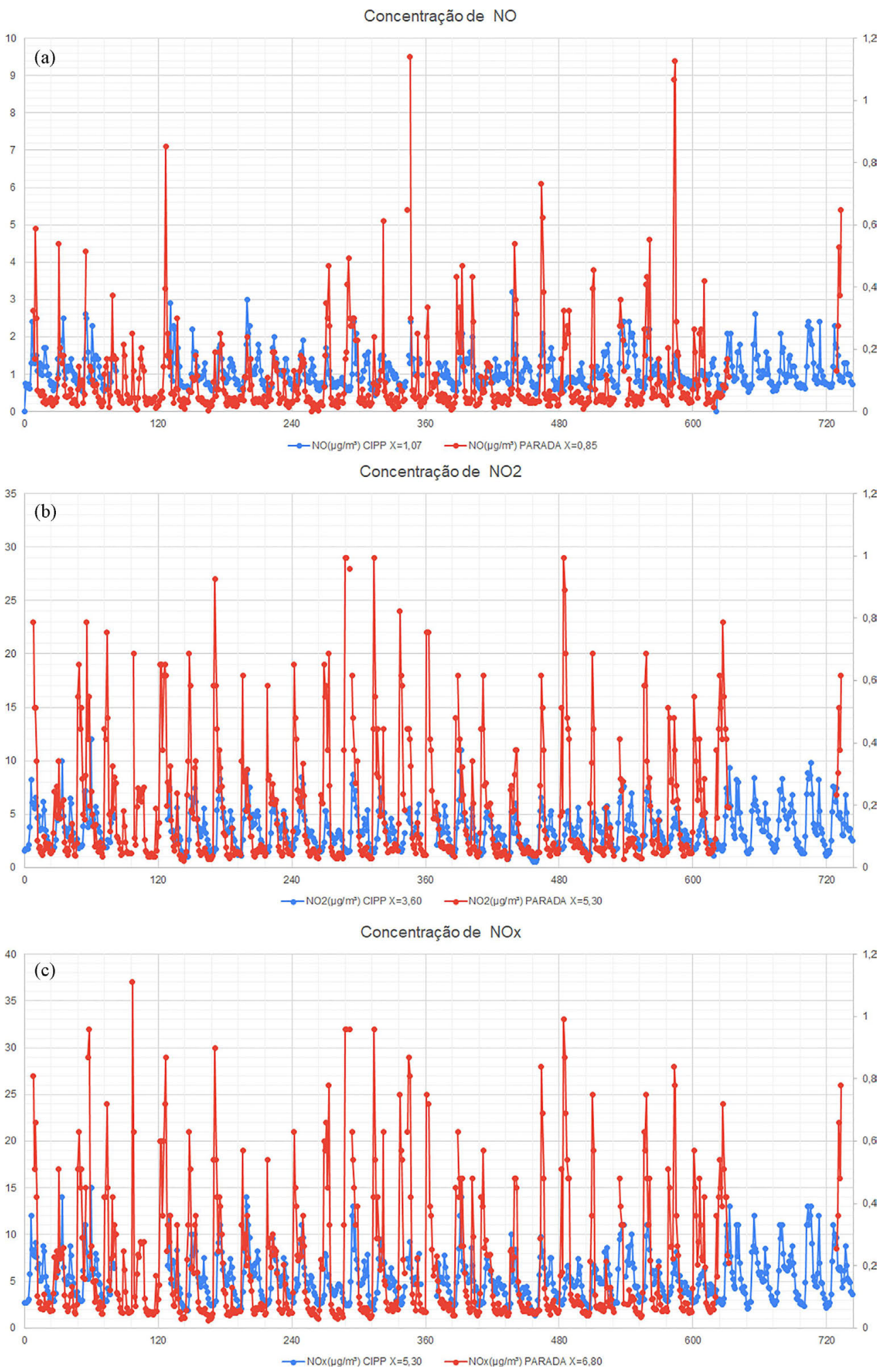

Figura 3 - Série temporal dos óxidos de Nitrogênio: (a) $\mathrm{NO}$, (b) $\mathrm{NO}_{2}$ e (c) $\mathrm{NO}_{\mathrm{x}}$ para as estações "UM-CIPP" e "UM-Parada". Período: 14 de agosto a 14 de setembro de 2019. Fonte: O Autor com dados da SEMACE (2019).

resultados apresentados no monitoramento da qualidade do ar estivessem em sua totalidade apresentando a condição boa.
Contudo, há de se considerar as constatações da população local, já evidenciadas nas notícias veiculadas na imprensa e aprofundar os estudos na área para ratificar de 


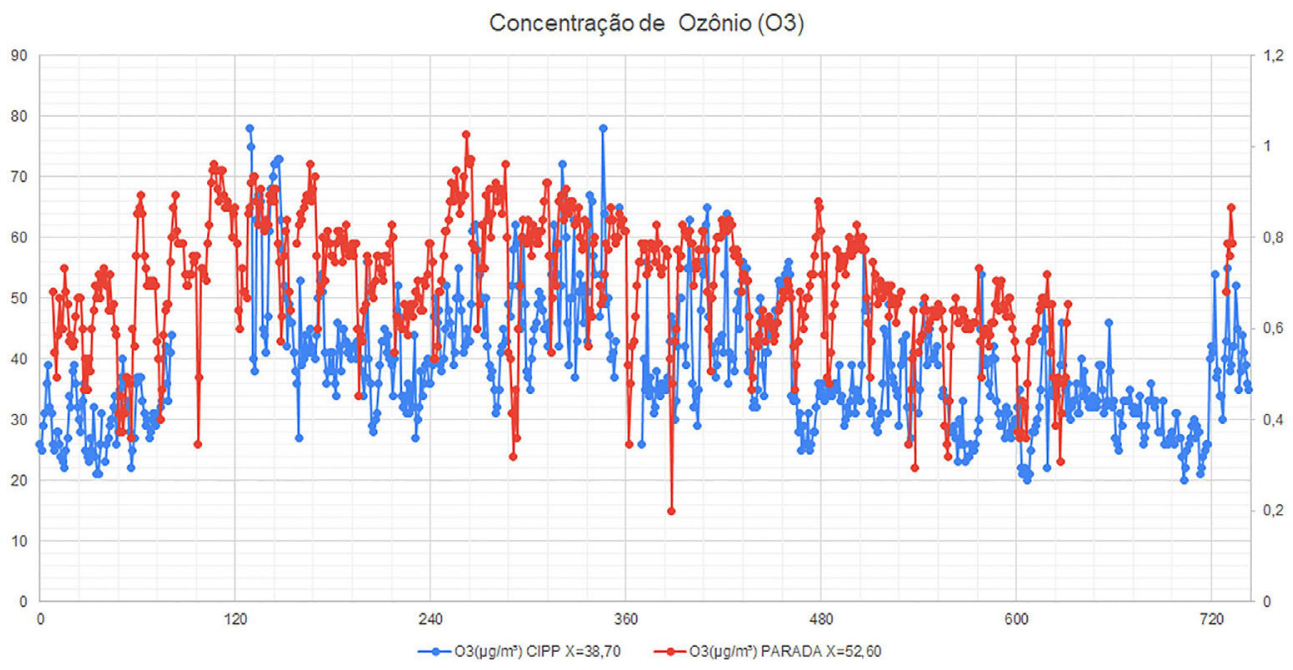

Figura 4 - Série temporal da Concentração de Ozônio $\left(\mathrm{O}_{3}\right)$, Estação "CIPP” e "UM-Parada". Período: 14 de agosto a 14 de setembro de 2019. Fonte: $\mathrm{O}$ Autor com dados da SEMACE (2019).

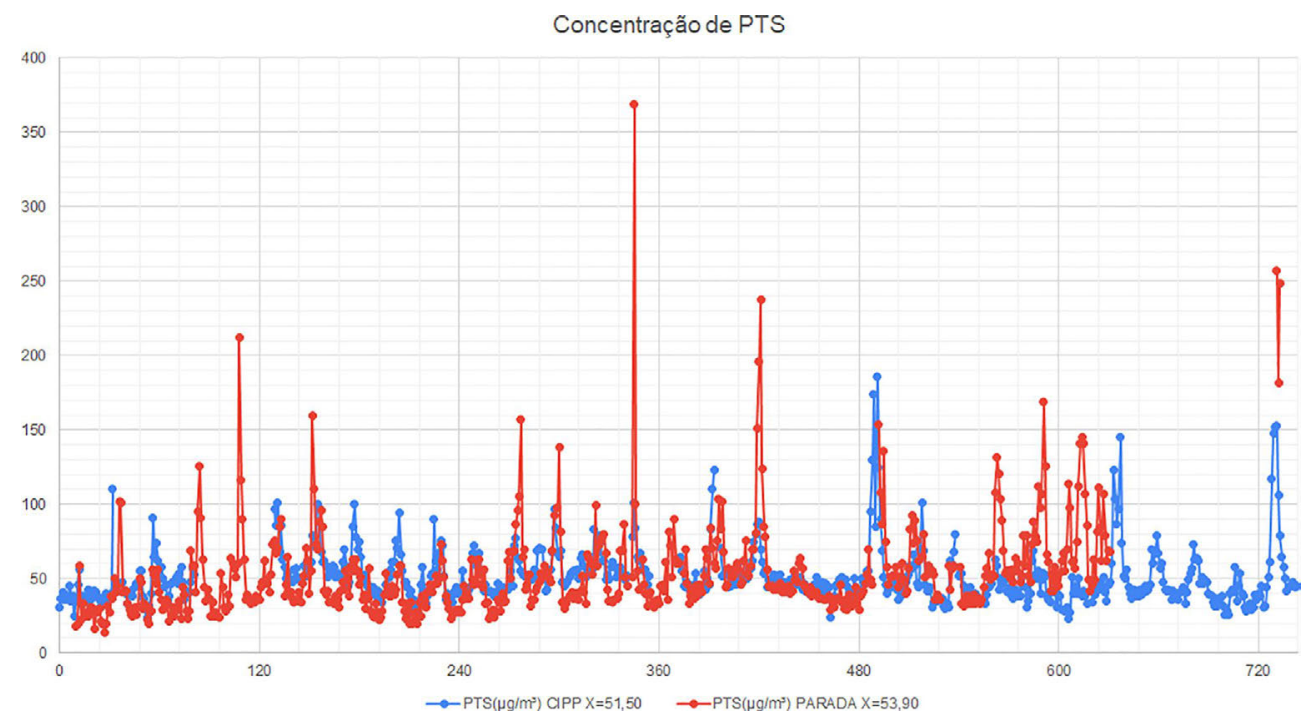

Figura 5 - Série temporal da concentração de Partículas em Suspensão Totais (PTS) - Estações UM-CIPP e UM-Parada. Período 14 de agosto a 14 de setembro de 2019. Fonte: O Autor com dados da SEMACE (2019).

fato, o elevado potencial poluidor-degradador das instalações industriais.

\subsection{Modelagem computacional de deposição de poluentes}

As simulações realizadas para verificar as áreas de deposição dos poluentes que saem da CSP, também considerando a chaminé da sinterização, foi realizada para um dia de cada mês (agosto e setembro de 2019), devido aos dados da grade global (Global Forecast System) GFS 0,25 para a aplicação HYSPLIT ${ }^{\circledR}$ estarem disponíveis nesta resolução apenas a partir de 06/2019. Neste caso, foi escolhido nestas duas simulações, o dia 14 de cada mês, sem motivo específico para escolha do dia, foi arbitrado pelo autor, e resultaram gráficos em forma de nuvem de deposi- ção direcionadas para noroeste, sobrepondo em ambas as vezes, como local de destino a comunidade da Parada.

A deposição (forward trajectories) partindo da posição da chaminé da siderúrgica CSP estão apresentados nos gráficos individualmente para o dia 14 de agosto e 14 de setembro de 2019 respectivamente nas Figs. 7 e 8.

A observação dos gráficos permite depreender um aspecto interessante a respeito do poluente que é a concentração depositada na área de dispersão, por exemplo: a maior taxa de deposição é a cor amarela que representa taxa > $1.0 \mathrm{E}-9 \mathrm{mass} / \mathrm{m}^{2}$; E vai diminuindo, a cor azul representa $>1.0 \mathrm{E}-10 \mathrm{mass} / \mathrm{m}^{2}$; a cor verde representa $>1.0$ E-11 mass $/ \mathrm{m}^{2}$. Ou seja, a taxa de deposição vai diminuindo à medida que se afasta da fonte de lançamento do poluente. 


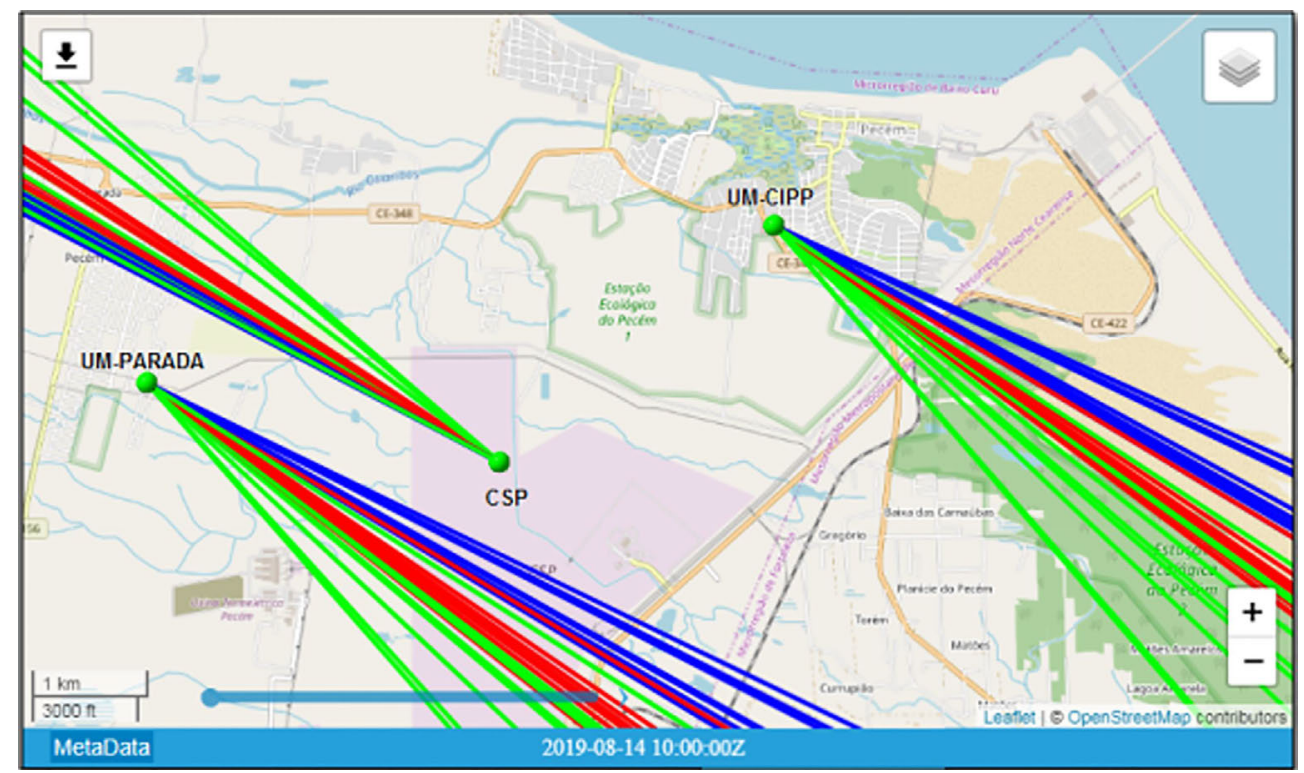

Figura 6 - Representação das trajetórias das emissões da CSP e trajetórias reversas, a partir das estações "UM-CIPP" e "UM-PARADA", simuladas pelo programa HYSPLIT ${ }^{\circledR}$ com início em 14 de agosto de 2019 (com tempo de 4 horas tanto para projeção quanto para reversão). Fonte: HYSPLIT ${ }^{\circledR}$

Uma estimativa para a extensão dessa maior taxa de deposição de cor amarela é de aproximadamente $2 \mathrm{~km}$ na Fig. 7 e vai até pouco mais de $3 \mathrm{~km}$ na Fig. 8 na linha de centro da pluma. Já para a extensão da segunda maior taxa de deposição de cor azul, esta representa taxa > 1.0 E-10 mass $/ \mathrm{m}^{2}$ e de aproximadamente $15 \mathrm{~km}$.

A partir da definição da quantidade de poluentes liberada em unidade de massa, as concentrações resultantes representarão um fator de diluição em vez de concentrações reais de ar e também fornecerão uma "pegada" do padrão de dispersão. Uma vez conhecido o termo fonte, o usuário final pode multiplicá-lo pelas concentrações do modelo resultante (fatores de diluição) para obter concentrações de ar.

Sintetizando, as simulações resultaram em gráficos de nuvens de deposição direcionadas para oeste e noroeste, sobrepondo quase que constantemente a comunidade de Parada e indo muito além, sobrepondo embora com menor concentrações de poluentes, vários municípios do litoral Oeste do Ceará.

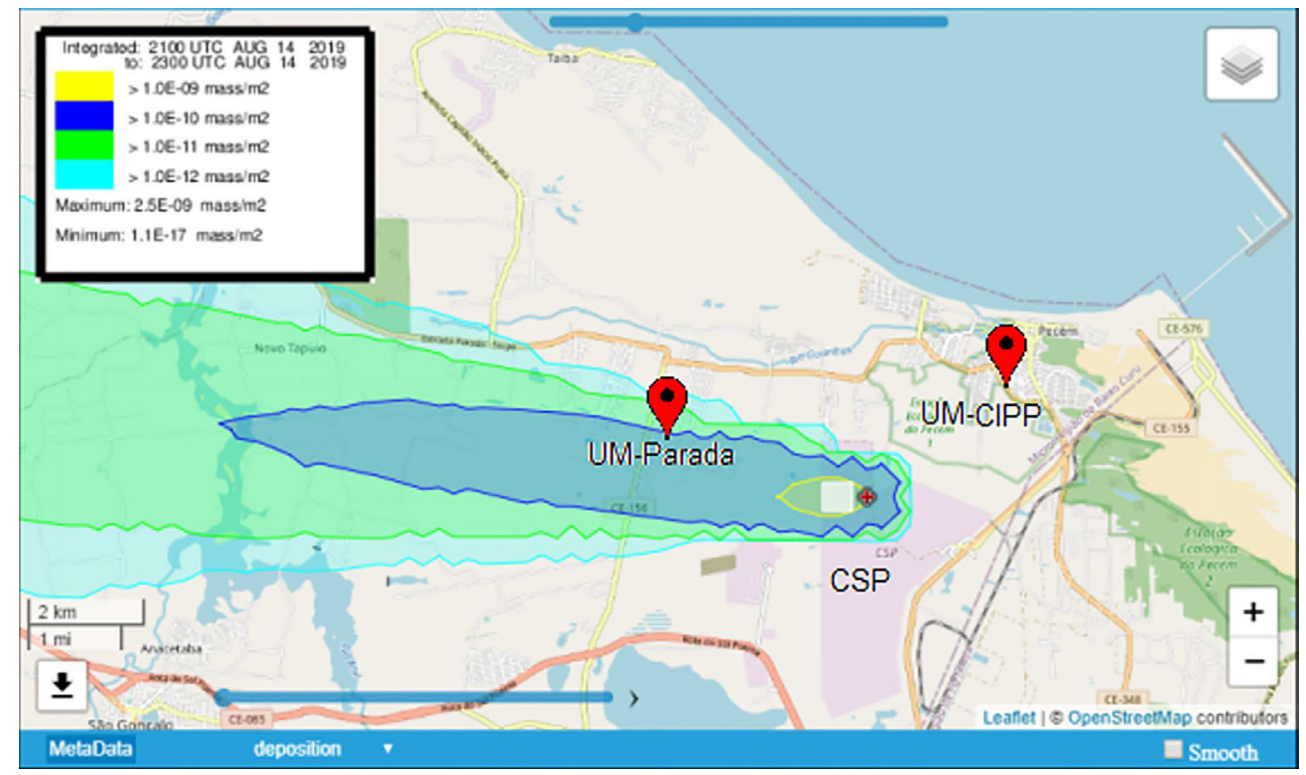

Figura 7 - Modelagem computacional da deposição de poluentes através da aplicação HYSPLIT ${ }^{\circledR}$ para o dia 14 de agosto de 2019. Fonte: HYSPLIT ${ }^{\circledR}$ (2020). 


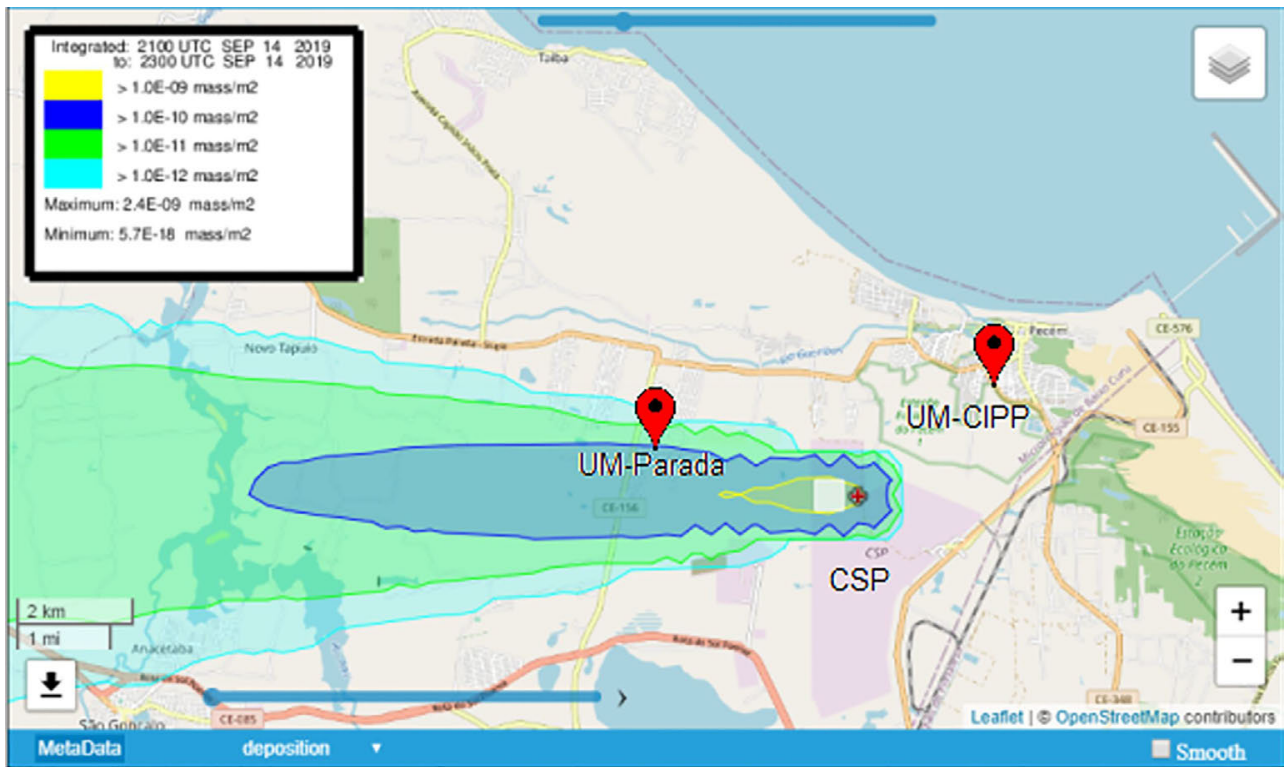

Figura 8 - Modelagem computacional da deposição de poluentes através da aplicação HYSPLIT ${ }^{\circledR}$ para o dia 14 de setembro de 2019. Fonte: HYSPLIT ${ }^{\circledR}$ (2020).

Esta técnica de investigação do processo de deposição de poluentes atmosféricos utilizando modelos computacionais mostrou-se de utilização simples e intuitiva e considera-se que tenha sido empregada com sucesso na compreensão do processo de dispersão de poluentes. A realização das simulações permitiu saber que os impactos vão, na realidade, muito além da comunidade vizinha a fonte poluidora.

\section{Conclusão}

A análise dos dados referente aos gases e poluentes atmosféricos associada às simulações de transporte e dispersão na área de influência do CIPP, no período de estudo nos leva às seguintes considerações:

- Os resultados do monitoramento do gás Metano $\left(\mathrm{CH}_{4}\right)$, caracterizam o ar como limpo nas imediações da estação "UM-CIPP" e valores limítrofes tendendo ao poluído no entorno da "UM-Parada", sendo sugestivo a provável associação da alteração na concentração média do metano com a instalação industrial objeto deste estudo.

- Em relação ao monitoramento dos gases poluentes: Ozônio $\left(\mathrm{O}_{3}\right)$; aos óxidos de Nitrogênio $\left(\mathrm{NO} / \mathrm{NO}_{2} / \mathrm{NOx}\right)$ e as Partículas Totais em Suspensão (PTS); o ar pode ser enquadrado como limpo nas imediações de ambas as estações "UM-CIPP" e "UM-Parada", embora o valor medido por esta última seja maior que na primeira, os valores estão bem abaixo do especificado como limites na Resolução CONAMA N ${ }^{\circ}$. 491/2018 em referência ao padrão da qualidade do ar, indicando uma legislação muito permissiva.
- O uso do modelo computacional de simulação de trajetórias de dispersão associado a simulação de trajetórias reversas permitiram verificar onde seria a mais adequada localização para as estações de monitoramento da qualidade do ar.

- Este estudo também permite concluir que a comunidade da Parada é afetada diretamente pela presença destas indústrias na região, já sendo reconhecido em pequena parte o efeito degradador, pelas constantes lutas da comunidade.

\section{Referências}

BRASIL. Ministério do Meio Ambiente. Conselho Nacional do Meio Ambiente. Resolução CONAMA Nº 491 de 19 de Novembro de 2018. Dispõe sobre padrões de qualidade do ar.

CSP, Companhia Siderúrgica do Pecém. Sobre a CSP - Nossa História. Disponível em: https://www.cspecem.com/pt-br/ sobre-a-csp/nossa-historia/. Acesso em: 03 out. 2019.

DIÁRIO DO NORDESTE. Moradores do Pecém voltam a sofrer com fuligem de carvão mineral da CSP. Jornal Diário do Nordeste, Fortaleza, 28 out. 2019, 18:47 Negócios. Disponível em https://diariodonordeste.verdesmares.com.br/ editorias/negocios/online/moradores-do-pecem-voltam-asofrer-com-fuligem-de-carvao-mineral-da-csp-1.2167561 Acesso em 15 fev. 2020.

FERREIRA JÚNIOR, A.C. Avaliação da Qualidade do Ar no Município de São Gonçalo do Amarante/CE. Dissertação de Mestrado, Programa de Pós-Graduação em Tecnologia e Gestão Ambiental, IFCE, Fortaleza, 2016.

MIHELCIC, J.R.; ZIMMERMAN, J.B. Engenharia Ambiental: Fundamentos, Sustentabilidade e Projeto. $2^{\text {a }}$ ed. Rio de Janeiro: Editora LTC, 2018. 
NOAA, HYSPLIT. Disponível em https://www.ready.noaa.gov/ hysplit_metadata.html. Acesso em 16 fev. 2020.

OLIVEIRA, S. Estudo de Dispersão Atmosférica. Relatório Técnico. Fortaleza: Instituto Centro de Ensino Tecnológico, 2010. Disponível em https://docplayer.com.br/ 17942981-Complexo-industrial-do-pecem-cip-estudo-dedispersao-atmosferica.html. Acesso em 21 fev. 2020.

OLIVEIRA, A.A.B. Inventário das Emissões Atmosféricas na Indústria Siderúrgica. Monografia de Graduação em Engenharia Metalúrgica, Escola Politécnica, UFRJ, Rio de Janeiro, 85 p., 2014.

OPOVO. Poluição no Pecém causa retirada de famílias do entorno. Jornal O Povo Online, Fortaleza, 27 jul. 2018. Disponível em: https://www.opovo.com.br/jornal/econo $\mathrm{mia} / 2018 / 07 /$ poluicao-no-pecem-causa-retirada-de-famil ias-do-entorno.html Acesso em 15 fev. 2020.

SEMACE. Servicos, Qualidade do Ar. Disponível em https:// www.troposfera.es/br/referencias-2/siam-estado-de-ceara/ indice-de-qualidade-do-ar.html. Acesso em 19 ago. 2019.

SEMACE. Controle ambiental da CSP. Disponível em https:// www.semace.ce.gov.br/2017/06/09/semace-acompanharacontrole-ambiental-da-csp/. Acesso em 3 out. 2019.

SEMACE. Qualidade do Ar na região do Porto do Pecém é Positiva. Disponível em https://www.semace.ce.gov.br/ 2019/01/23/qualidade-do-ar-na-regiao-do-porto-do-peceme-positiva/. Acesso em 15 fev. 2020.
SILVA, C. Modelagem Lagrangeana da Dispersão Atmosférica de Radionuclídeos e Sistemas de Informação Geográfica como Ferramentas de Suporte ao Planejamento de Emergência na Área de Influência do Complexo nuclear de Angra dos Reis - RJ. Rio de Janeiro: UFRJ/ COPPE, 251 p., 2013. Disponível em https://inis.iaea.org/ collection/NCLCollectionStore/_Public/45/004/45004885. pdf. Acesso em 22 fev. 2020.

SILVA, J.R.; MIRANDA, P.T.C.; PITOMBEIRA, S.C.; FREIRE, G.S.S. Complexo Industrial e Portuário do Pécem, Município de São Gonçalo do Amarante, Ceará- Brasil: Considerações em Torno de sua Avaliação Ambiental Estratégica. Arq. Ciências do Mar, v. 47, n. 2, p. 86-93, 2014.

STEIN, A.F.; DRAXLER, R.R.; ROLPH, G.D.; STUNDER, B.J.B.; COHEN, M.D.; NGAN, F. NOAA's HYSPLIT atmospheric transport and dispersion modeling system. Bull. Amer. Meteor. Soc., v. 96, n. 12, p. 2059-2077, 2015.

\section{Endereços de Internet}

HYSPLIT $^{\circledR}$, https://www.ready.noaa.gov/HYSPLIT.php.

License information: This is an open-access article distributed under the terms of the Creative Commons Attribution License (type CC-BY), which permits unrestricted use, distribution and reproduction in any medium, provided the original article is properly cited. 